\title{
Effect of Reproductive, Menstrual and Familial Factors on The risk of Breast Cancer pre and post Menopause
}

\author{
Treza S. Badia, Ghadah A. Mahmoud, \& Mohamed A. Salem
}

Demonestrator of Obstetrics \& Gynecological Nursing, Faculty of Nursing, Assuit University, Egypt. Assistant Professor of Obstetrics\& Gynecological Nursing, Faculty of Nursing, Assuit University, Egypt. Assistant Professor of Surgical Oncology South Egypt Cancer Institute, Assuit University, Egypt.

\begin{abstract}
Background: Breast cancer is the most common cancer among women in developed and developing countries. Reproductive factors are associated with higher risk for breast cancer. Aim of the study: To clarify the effect of reproductive, menstrual and familial factors on the risk of breast cancer, pre and post menopause. Subjects and Methods: A case-control study design was used in this study and convenient sample for the women selection, the sample comprised 300 women that divided into two main groups, 150 for each group, Study group and control groups. Completing questionnaire from all women. Results: The study revealed statistically significant associations between breast cancer and age, family history, late age at menopause $(\mathrm{p}<0.001)$, early age at menarche, $(\mathrm{p}<0.009)$, longer cycle duration $(\mathrm{p}<0.001)$, contraceptive pills $(\mathrm{p}<0.017)$, also the result revealed that there was no statistically significant between these factors and breast cancer regarding menopausal status. Conclusion: the findings of the present study support that there is a statistically significant relation between some of reproductive, menstrual, familial factors, and breast cancer. Recommendation: Health education programs regarding breast cancer, risk factors and early detection. Nurses should provide practical training in breast self-examination, especially for those women who are at higher risk of breast cancer.
\end{abstract}

\section{Key words: Cancer, Breast Cancer \& Reproductive Risk Factors.}

\section{Introduction}

Breast cancer is a kind of cancer that develops from breast cells. It usually starts in the inner lining of milk ducts or the lobules that supply them with milk. A breast cancer that started in the lobules is known as lobular carcinoma, while one that developed from the ducts is called ductal carcinoma. (Wiechmann et al., 2008)

It is the most common invasive cancer in females worldwide. It accounts for $16 \%$ of all female cancers and $22.9 \%$ of invasive cancers in women. $18.2 \%$ of all cancer deaths worldwide, including both males and females, are from breast cancer. (Howlader et al., 2012)

While breast cancer is a global issue, in Egypt, the figure for people suffering from breast cancer is alarming. It is the commonest cancer among Egyptian women and represents $35.1 \%$ of all female cancers .It is estimated that one in nine Egyptian families will be affected by breast cancer. (Aboserea et al., 2011) Breast cancer rates are much higher in developed nations compared to developing ones. There are several reasons for this, with possibly life expectancy being one of the key factors and it is more common in elderly women; women in the richest countries live much longer than those in the poorest nations. The different lifestyles and eating habits of females in rich and poor countries are also contributory factor. (James 2012)
Breast cancer risk is around doubled in women with one first- degree relative with breast cancer, compared with women with no first- degree relatives. Environmental and life style factors explain around three- quarters of breast cancer risk, with hereditary factors explaining only around quarter. The reasons for breast cancer clustering in families remain largely unclear. (Afonso, 2009)

The role of reproductive and menstrual factors as a risk of breast cancer has long been recognized.

(Trivers et al., 2007) As regards age at menarche, some studies have found a stronger inverse relationship in women with premenopausal breast cancer than in those diagnosed after menopause. Other studies have indicated that early menarche is a weak risk factor for all age groups. (Walker et al., 2011)

Several lines of evidence suggest that late age at menopause is an important risk factor for breast cancer. In one study, the increased risk associated with late age at natural menopause was not apparent until 65 years of age, thus suggesting a 10-20 year delay of its effect, but the time- risk relationship for age at menopause is still open. By large, prolonged exposure to sex hormones, as indicated by a high number of reproductive years from menarche to menopause, 
has been suggested to increase breast cancer risk. (Flesch et al., 2008)

Early age at first birth has conferred, in most studies, persistent protection. However, first birth after age 30, appears to be associated with a breast cancer risk higher than that in nulliparous women . An explanation for these findings is that an early full-term pregnancy reduces the likelihood of cancer initiation, but at a later age it may promote the growth of existing cancer cells. (Britt et al., 2007)

Nulliparity has consistently emerged as a risk factor for breast cancer Some studies, which considered age at cancer diagnosis, have found that the elevated risk is confined to nulliparous older women. Parous women seem to be at increased risk during the 10-15 years subsequent to a pregnancy as compared with nulliparous women.( Albrektsen et al., 2006)

The influence of spontaneous or induced abortions on the risk of breast cancer remains unclear . Some studies have shown some moderate positive associations, while others have suggested no clear relationship. (Michels et al., 2007)

\section{The Aim of the study}

The aim of the study was to clarify the effect of reproductive, menstrual and familial factors on the risk of breast cancer, pre and post menopause

Research question

What is the effect of reproductive, menstrual and familial factors on the risk of breast cancer, pre and post menopause?

\section{Subject and methods}

Research design

A case-control study design was used in this study.

\section{Setting}

The study was conducted at South Egypt Cancer Institute, Assiut University at Outpatient Clinics and female surgical ward for study group which its capacity in total (2642) cases annually, (449) cases from them were breast cancer and Eleman Specialized Hospital for control group

\section{Sample}

This study used convenient sample which comprised 300 women that divided into two main groups according to women's diagnosis, 150 for each group, study and control group. Study group included 150 women who had been diagnosed with breast cancer at South Egypt Cancer Institute, Assiut University and control group which included 150 women who suffer from other gynecological disorders and attending at Eleman Specialized Hospital.

\section{Sample size}

Women were allocated to this study according to sample size equation. The sample was calculated using Epi- Info statistical package, version3.3 with power $80 \%$ a value of 2.5 is chosen as the acceptable limit of precision (D) at $95 \%$ level of confidence(CI), with expected prevalence $20 \%$, and worst acceptable $16 \%$. Accordingly, sample size was estimated to be $234+10 \%$ individuals to guard against nondespondence rate. The computed sample size plus expected dropout rate was 300(150 study group and 150 control group).

Tools of the study

The following tool was used in the current study

A Structured interviewing questionnaire

which included the following data

- Part (A) Socio-demographic data: such as name, age, occupation, address, date of admission, educational level, residence, marital status.

- Part (B) Family history: history of chronic diseases as diabetes, hypertension, heart diseases and family history of breast cancer as well as consanguinity.

- Part (C) Menstrual history: age at menarche, amount and duration of menstruation, length of the cycle, interval and regularity.

- Part (D) Obstetric history: gravidity, parity, age at first labor, stillbirths, and live births, breastfeeding, complications related to previous deliveries and history of previous abortions.

- Part (E) History of using the family planning methods, its type, duration of use, its side effect if found and causes of termination.

- Part (F) Medical history: history of chronic diseases as diabetes, hypertension, heart diseases, etc.

- Part (G) History of breast cancer time of onset, recurrence, type, symptoms and signs, treatment modality and risk factors

\section{Procedure}

Before implantation of the study, an official permission was obtained from the Dean of South Egypt Cancer Institute, Assuit University, and from the general director Eleman Specialized Hospital as well as an ethical approval from the ethical committee of Faculty of nursing, Assuit University. The investigator explained the nature and the aim of study then verbal informed consent was taken from every woman before inclusion in the study.

The main procedure for data collection was through personal and single face-to face interview with every case. Before conducting the study, an exploratory visit was done in surgical units in order to estimate the rate of admission and suitable time for collecting data according to each unit. Besides, personal 
communication was done with nurses and physician to explain the purpose of the study and gain their best possible cooperation.

The data was collected four days a week, time taking for every case was 20 minutes. The full history was taken as it was in the structured questionnaire which included information for Socio-demographic data, menstrual and reproductive history (e.g. age at menarche, menopausal status, age at menopause, type of menopause, parity, abortions, age at first live birth and length of attempt to first pregnancy), medical history, history of contraceptives using , history of menopausal symptoms and predisposing factors of breast cancer. Every question was addressed to the case and the responses were recorded.

Then the investigator gave each case in study group health education about the Predisposing factors of breast cancer which include family history of breast disease, age, obesity, radiation exposure, dietary factors and Hormonal Replacement Therapy ( H R $\mathrm{T}$ ), nutrition, activity, relaxation technique and pain management .

\section{Statistical Analysis}

The data were tested for normality using the Anderson-Darling test and for homogeneity variances prior to further statistical analysis. Categorical variables were described by number and percent $(\mathrm{N}, \%)$, where continuous variables described by mean and standard deviation (Mean, SD). Chisquare test was used to compare between categorical variables where compare between continuous variables by unpaired t-test. A twotailed $\mathbf{p}<0.05$ was considered statistically significant. All analyses were performed with the IBM SPSS 20.0 software.

\section{Ethical considerations}

- Research proposal would be approved from Ethical Committee in the Faculty of Nursing

- There was no risk for study subject during application of the research.

- The study followed common ethical principles in clinical research

- Oral consent was obtained from patient or guidance that is willing to participate in the study

- Confidentiality and anonymity was assured.

- Study subjects had the right to refuse to participate and /or to withdraw from the study without any rational any time.

- Study subject privacy were considered during collection of data 


\section{Results}

Table 1: Sociodemographic characteristics of study and control groups.

\begin{tabular}{|c|c|c|c|c|c|}
\hline \multirow{2}{*}{ Sociodemographic characteristics } & \multicolumn{2}{|c|}{ Cases $(n=150)$} & \multicolumn{2}{|c|}{ Control $(n=150)$} & \multirow{2}{*}{ P. value } \\
\hline & No. & $\%$ & No. & $\%$ & \\
\hline Age & \multicolumn{2}{|c|}{$48.9+12.1$} & \multicolumn{2}{|c|}{$31.6 \pm 7.2$} & $<0.001 * *$ \\
\hline $20>30$ years & 7 & 4.7 & 72 & 48 & \\
\hline $30>40$ years & 23 & 15.3 & 61 & 40.7 & \\
\hline $40>50$ years & 46 & 30.7 & 11 & 7.3 & $<0.001 * *$ \\
\hline $50+$ years & 74 & 49.3 & 6 & 4 & \\
\hline \multicolumn{6}{|l|}{ Marital status } \\
\hline Single & 12 & 8 & 4 & 2.7 & \multirow{4}{*}{$<0.001 * *$} \\
\hline Married & 102 & 68 & 144 & 96 & \\
\hline Divorced & 4 & 2.7 & 0 & 0 & \\
\hline Widow & 32 & 21.3 & 2 & 1.3 & \\
\hline \multicolumn{6}{|l|}{ level of education } \\
\hline Illiterate & 121 & 80.7 & 74 & 49.3 & \multirow{4}{*}{$<0.001 * *$} \\
\hline Basic education & 7 & 4.7 & 26 & 17.3 & \\
\hline Secondary & 20 & 13.3 & 38 & 25.3 & \\
\hline University & 2 & 1.3 & 12 & 8 & \\
\hline \multicolumn{6}{|l|}{ Occupational status } \\
\hline House wife & 150 & 100 & 147 & 98 & \multirow{2}{*}{0.082} \\
\hline Employer & 0 & 0 & 3 & 2 & \\
\hline
\end{tabular}

Table (2): Obstetric history of study and control groups.

\begin{tabular}{|c|c|c|c|c|c|}
\hline & \multicolumn{2}{|c|}{ Cases $(n=138)$} & \multicolumn{2}{|c|}{ Control $(n=146)$} & \multirow{2}{*}{ P. value } \\
\hline & No. & $\%$ & No. & $\%$ & \\
\hline Gravidity & \multicolumn{2}{|c|}{$6.3+3.8$} & \multicolumn{2}{|c|}{$4.3+2.6$} & $<0.001 * *$ \\
\hline 1 & 3 & 2.2 & 11 & 7.5 & \\
\hline $2-4$ & 26 & 18.8 & 76 & 52.1 & $<0.001 * *$ \\
\hline $5+$ & 109 & 79 & 59 & 40.4 & \\
\hline Parity & \multicolumn{2}{|c|}{$5.1 \pm 2.3$} & \multicolumn{2}{|c|}{$3.9 \pm 1.9$} & $<0.001 * *$ \\
\hline Nulliparous & 6 & 4.3 & 7 & 4.8 & \multirow{4}{*}{$<0.001 * *$} \\
\hline Primipara & 4 & 2.9 & 11 & 7.5 & \\
\hline $2-4$ & 50 & 36.3 & 87 & 59.6 & \\
\hline $5+$ & 78 & 56.5 & 41 & 28.1 & \\
\hline Abortion & \multicolumn{2}{|c|}{$2.1 \pm 1.5$} & \multicolumn{2}{|c|}{$2.5 \pm 2.5$} & 0.234 \\
\hline 0 & 64 & 46.4 & 106 & 72.6 & \multirow{4}{*}{$<0.001 * *$} \\
\hline 1 & 34 & 24.6 & 23 & 15.8 & \\
\hline $2-4$ & 35 & 25.4 & 12 & 8.2 & \\
\hline $5+$ & 5 & 3.6 & 5 & 3.3 & \\
\hline Stillbirth & \multicolumn{2}{|c|}{$1.8 \pm 1.2$} & \multicolumn{2}{|c|}{$1.7 \pm 0.6$} & 0.882 \\
\hline 0 & 108 & 81.8 & 136 & 97.9 & \multirow{4}{*}{$<0.001 * *$} \\
\hline 1 & 13 & 9.8 & 1 & 0.7 & \\
\hline 2 & 8 & 6.1 & 2 & 1.4 & \\
\hline $3+$ & 3 & 2.3 & 0 & 0 & \\
\hline Neonatal death & \multicolumn{2}{|c|}{$2.7 \pm 1.9$} & \multicolumn{2}{|c|}{$1.5 \pm 0.6$} & 0.239 \\
\hline 0 & 115 & 87.2 & 135 & 97.2 & \multirow{4}{*}{$0.009 * *$} \\
\hline 1 & 5 & 3.8 & 2 & 1.4 & \\
\hline 2 & 6 & 4.5 & 2 & 1.4 & \\
\hline $3+$ & 6 & 4.5 & 0 & 0 & \\
\hline
\end{tabular}




\begin{tabular}{|c|c|c|c|c|c|}
\hline & \multicolumn{2}{|c|}{ Cases $(n=138)$} & \multicolumn{2}{|c|}{ Control $(n=146)$} & \multirow{2}{*}{ P. value } \\
\hline & No. & $\%$ & No. & $\%$ & \\
\hline \multicolumn{6}{|c|}{ Age at first pregnancy } \\
\hline$<20$ & 59 & 42.7 & 50 & 36 & \multirow{3}{*}{0.511} \\
\hline $20-31$ & 78 & 56.6 & 88 & 63.3 & \\
\hline$\geq 32$ & 1 & 0.7 & 1 & 0.7 & \\
\hline \multicolumn{6}{|c|}{ Outcome of first pregnancy } \\
\hline Live birth & 105 & 76 & 111 & 79.9 & \multirow{4}{*}{$0.011 * *$} \\
\hline Stillborn & 10 & 7.2 & 1 & 0.7 & \\
\hline Neonatal death & 4 & 3 & 11 & 7.9 & \\
\hline Induced abortion & 19 & 13.8 & 16 & 11.5 & \\
\hline
\end{tabular}

$*$ Still birth no=132* Neonatal death no $=132$

Table (3): Menstrual history of study and control groups.

\begin{tabular}{|c|c|c|c|c|c|}
\hline \multirow{2}{*}{ Menstrual history } & \multicolumn{2}{|c|}{ Cases $(n=150)$} & \multicolumn{2}{|c|}{ Control $(n=150)$} & \multirow{2}{*}{ P. value } \\
\hline & No. & $\%$ & No. & $\%$ & \\
\hline \multicolumn{6}{|l|}{ Age at menarche } \\
\hline$\leq 15$ & 136 & 90.7 & 145 & 96.7 & \multirow{2}{*}{$0.033^{*}$} \\
\hline$>15$ & 14 & 9.3 & 5 & 3.3 & \\
\hline \multicolumn{6}{|l|}{ Duration days } \\
\hline 1-3 days & 37 & 24.7 & 24 & 16 & \multirow{3}{*}{$<0.001^{* *}$} \\
\hline $4-6$ days & 74 & 49.3 & 112 & 74.7 & \\
\hline$\geq 7$ days & 39 & 26 & 14 & 9.3 & \\
\hline \multicolumn{6}{|l|}{ Menstrual cycles } \\
\hline$<26$ & 42 & 28 & 19 & 12.7 & \multirow{3}{*}{$<0.001 * *$} \\
\hline $26-30$ & 98 & 65.3 & 128 & 85.3 & \\
\hline$>30$ & 10 & 6.7 & 3 & 2 & \\
\hline \multicolumn{6}{|l|}{ Regularity } \\
\hline Regular & 129 & 86 & 130 & 86.7 & \multirow{2}{*}{0.866} \\
\hline Irregular & 21 & 14 & 20 & 13.3 & \\
\hline \multicolumn{6}{|l|}{ Amount } \\
\hline Scanty & 10 & 6.7 & 13 & 8.7 & \multirow{3}{*}{$<0.001 * *$} \\
\hline Moderate & 62 & 41.3 & 107 & 71.3 & \\
\hline Heavy & 78 & 52 & 30 & 20 & \\
\hline \multicolumn{6}{|l|}{ Menstrual disorders } \\
\hline $\mathrm{No}$ & 35 & 23.3 & 77 & 51.3 & \multirow{2}{*}{$<0.001 * *$} \\
\hline Yes & 115 & 76.7 & 73 & 48.7 & \\
\hline
\end{tabular}

Table (4): Predisposing factors of breast cancer of study and control groups.

\begin{tabular}{|c|c|c|c|c|c|}
\hline & \multicolumn{2}{|c|}{ Study $=\mathbf{1 5 0}$} & \multicolumn{2}{|c|}{ Control $=\mathbf{1 5 0}$} & \multirow[t]{2}{*}{ P. value } \\
\hline & No. & $\%$ & No. & $\%$ & \\
\hline \multicolumn{6}{|c|}{ predisposing factors of breast cancer which include } \\
\hline No risk factors & 0 & 0.0 & 103 & 68.6 & $<0.001 * *$ \\
\hline Family history of breast cancer & 30 & 20.0 & 7 & 4.7 & $<0.001 * *$ \\
\hline Age (more than 40 years) & 97 & 64.7 & 11 & 7.3 & $<0.001 * *$ \\
\hline Using oral contraceptive pills ( $>5$ years) & 15 & 10.0 & 4 & 2.7 & $0.017 *$ \\
\hline HRT & 0 & 0.0 & 0 & 0.0 & - \\
\hline Dietary factors(bad habits, as fatty food) & 14 & 9.3 & 8 & 5.3 & 0.268 \\
\hline Early menarche (<10 years $)$ & 21 & 14.0 & 7 & 4.7 & $0.009 * *$ \\
\hline Late menopause( $\geq 55$ years $)$ & 15 & 10.0 & 1 & 0.7 & $<0.001 * *$ \\
\hline Nulliparous and late pregnancy ( $>30$ years) & 17 & 11.3 & 9 & 6.0 & 0.151 \\
\hline
\end{tabular}

\# More than one available 
Table (5): Relation of predisposing factors of breast cancer among menopausal and non-menopausal cases in study group.

\begin{tabular}{|c|c|c|c|c|c|}
\hline & \multicolumn{4}{|c|}{ Study group $=150$} & \multirow[t]{3}{*}{ P. value } \\
\hline & \multicolumn{2}{|c|}{ Menopause $=78$} & \multicolumn{2}{|c|}{ Non menopause $=72$} & \\
\hline & No. & $\%$ & No. & $\%$ & \\
\hline \multicolumn{6}{|c|}{ Predisposing factors of breast cancer which include } \\
\hline Family history of breast cancer & 15 & 19.2 & 15 & 20.8 & 1.000 \\
\hline Age (more than 40 years) & 76 & 97.4 & 21 & 29.2 & $<0.001 * *$ \\
\hline Using oral contraceptive pills & 8 & 10.2 & 7 & 9.7 & 0.997 \\
\hline HRT & 0 & 0.0 & 0 & 0.0 & - \\
\hline Dietary factors & 2 & 2.6 & 12 & 16.7 & $<0.001 * *$ \\
\hline Early menarche & 11 & 14.1 & 10 & 13.9 & 0.998 \\
\hline Nulliparous and late pregnancy & 10 & 12.8 & 10 & 13.9 & 0.494 \\
\hline
\end{tabular}

\# More than one available

Table (6): Relation of predisposing factors of breast cancer among menopausal and non-menopausal cases in control group.

\begin{tabular}{|c|c|c|c|c|c|}
\hline & \multicolumn{4}{|c|}{ Control group $=150$} & \multirow[t]{3}{*}{ P. value } \\
\hline & \multicolumn{2}{|c|}{ Menopause $=9$} & \multicolumn{2}{|c|}{ Non menopause $=141$} & \\
\hline & No. & $\%$ & No. & $\%$ & \\
\hline \multicolumn{6}{|c|}{ predisposing factors of breast cancer which include } \\
\hline No risk factors & 0 & 0.0 & 120 & 81.6 & $<0.001 * *$ \\
\hline Family history of breast cancer & 2 & 22.2 & 5 & 3.5 & 0.286 \\
\hline Age (more than 40 years) & 9 & 100 & 2 & 1.4 & $0.011^{*}$ \\
\hline Using oral contraceptive pills & 0 & 0.0 & 4 & 2.8 & $0.034^{*}$ \\
\hline HRT & 0 & 0.0 & 0 & 0.0 & - \\
\hline Dietary factors & 3 & 33.3 & 5 & 3.5 & 0.617 \\
\hline Early menarche & 3 & 33.3 & 4 & 2.8 & 0.997 \\
\hline Nulliparous and late pregnancy & 3 & 33.3 & 6 & 4.3 & 0.344 \\
\hline
\end{tabular}

\# More

than one available

Table (1): as regard the age this table shows that nearly half of cases in study group $(49.3 \%)$ were in the age group 50+ years, compared to the control group (4\%).

Table (2): Regarding the obstetric history, this table points to statistically significant differences between study and control groups in the number of gravidity, parity, stillbirth, abortion and outcome of first pregnancy $(\mathrm{p}<0.001, \mathrm{p}<0.001, \mathrm{p}<0.001, \mathrm{p}<0.001, \mathrm{p}=$ $0.011)$

Table (3): this table shows that more than half of cases in study group $(76.7 \%)$ had menstrual disorders, compared to the control group $(48.7 \%)$.

Table (4): this table shows statistically significant differences between study and control groups regarding family history, age, using oral contraceptive pills, early menarche, and late menopause $(\mathrm{p}<0.001, \mathrm{p}<0.001, \mathrm{p}<0.017, \mathrm{p}<0.009$, $\mathrm{p}<0.001)$ respectively.

Table (5): this table shows statistically significant differences among menopausal and non-menopausal cases in study group regarding age and dietary factors $(\mathrm{p}=<0.001, \mathrm{p}<0.001)$ respectively

Table (6): this table shows statistically significant differences among menopausal and non-menopausal cases in control group regarding age and using oral contraceptive pills $\quad(\mathrm{p}=<0.001, \mathrm{p} \quad<0.001)$ respectively

\section{Discussion}

Breast cancer is the most common cancer among women in developed and developing countries (Ahmadian et al., 2012). In 2008, approximately 1.38 million new cases were diagnosed and approximately 458,000 deaths were recorded both in developed and developing countries (Iskandarsyah et al., 2014).

The rates of breast cancer have increased over the past two decades (Asnarulkhadi et al., 2012). The WHO estimates that by the year 2020, the number of cases of cancer will double in developing countries (Seth et al., 2012). 
The aim of the present study was to clarify the effect of reproductive, menstrual and familial factors on the risk of breast cancer, pre and post menopause. The analysis of the data of the present study showed that there is a statistically significant relationship between, reproductive, menstrual and familial factors on the risk of breast cancer.

According to the present study findings, several hormone-related factors were identified as having a direct significant association with breast cancer. Thus, it was revealed that women with early age of menarche, longer cycle duration, heavy amount and menstrual disorders were at more risk of breast cancer.

In agreement with this finding, (Kotsopoulos et al., 2005) in their study which was conducted in Italy about age at menarche and the risk of breast cancer in BRCA1 and BRCA2 mutation carriers, demonstrated that increasing breast cancer risk has been associated with early age of menarche .This was explained by that mean age of menarche was equal (15years).

In contrast with this finding, (Bulter et al., 2000) study which was conducted in California about menstrual risk factors and early-onset breast cancer found that women with a young age at menarche did not experience a significant increase in early-onset breast cancer risk. This was explained by that those women with an early age at menarche also tend to have other characteristics that put them at low risk for early-onset breast cancer such as not establishing regular menstrual cycles.

Concerning obstetric history, the present study showed relation of statistical significance between study and control groups in the number of gravidity, parity, stillbirth, abortion, outcome of first pregnancy and there was no statistical significance regarding null parity and late age of first birth.

These findings agree with study which carried out in North-West of Iran about birth intervals and breast cancer risk (Kauppila et al., 2009) who reported an increased risk of breast cancer with repeated pregnancies. This was explained by that short birth interval-associated excess breast cancer risk may be related to stimulatory effects of female steroid hormones produced during two closely connected pregnancies, or defective breast maturation owing to failures in breastfeeding.

In the same line (Dai et al., 2009) study about metaanalysis of the risk factors of breast cancer concerning reproductive factors and oral contraceptive use which was conducted in China showed that increase in the number of deliveries was a risk factor for breast cancer. Agreement of these findings was explained by that the mean age of the first pregnancy for both studies is nearly equal (20years).
The present study also investigated that there was significant relationship between abortion and breast cancer where more half women with breast cancer had previous abortion, compared to less than onethird of the control group.

A woman's risk of developing breast cancer may be related to hormone levels in her body. Breast cells normally grow and divide in response to the levels of certain hormones, such as estrogen, progesterone, and prolactin. Levels of these hormones change throughout a woman's life, but can change a great deal during pregnancy. When a woman is pregnant, her body begins to prepare for breastfeeding by altering the levels of these hormones. This could cause changes in the breast tissue (Stefanidou et al., 2009).

In agreement with this present study finding, (Ozmen et al., 2009) study about breast cancer risk factors in Turkish women, concluded that a possible link between abortion and breast cancer have been raised because abortion is thought to interrupt the normal cycle of hormones during pregnancy. This interruption is believed by some to increase a woman's risk of developing breast cancer.

On the other hand, a recent report of the American Commission of Obstetrics and Gynecology had a report denying the relationship between breast cancer and induced abortion. The report indicated that the relationship between induced abortion and the subsequent development of breast cancer has been the subject of a substantial amount of epidemiologic study. (Committee on Gynecologic Practice, 2009). The present study has also investigated the possible risk associated with the use of contraception in the occurrence of breast cancer. Generally, the history of use of contraception did not differ significantly between cases with and without breast cancer. However, the duration of use of oral contraceptive pills was much more among women with breast cancer, and the difference was statistically significant.

These findings agree with a study carried out in London, Oral contraceptives and the risk of death from breast cancer (Wingo et al., 2007) stated that the association between estrogen and an increased risk of breast cancer led to a continuing debate about the role birth control pills might play in developing breast cancer. They highlighted that if the ovaries are removed early, for any reason, estrogen levels drop and the risk of breast cancer drops greatly. Therefore, since a woman's own hormones have an impact on the development of breast cancer, it is quite logical that taking hormone pills, particularly estrogen containing pills, might also have an impact on the risk of breast cancer. 
The present study has also found that there was a statistically significant difference between cases in study and control group regarding age at menopause. In an agreement with this findings Bernstein, (2002) have concluded that risk of breast cancer increases by $2.7 \%$ for every late menopause year. Also, a Chinese study showed that there was a significant relationship between breast cancer and age at menopause .It found that menopause after 50 years of age increased risk of breast cancer (Tam et al., 2010). This agreement in findings was explained that mean age at diagnosis of breast cancer was equal.

The present study also showed that there was a statistically significant difference between cases in study and control group regarding family history of breast cancer. In the same line (Antoniou et al., 2006) study about Parity and breast cancer risk among BRCA1 and BRCA2 mutation carriers which was conducted in Singapore, concluded that the risk of breast cancer increased progressively with numbers of affected relatives.

This finding agree with study which was conducted in New York, about natural history and pretreatment assessment of breast cancer which investigated that women with positive family history of breast cancer are about two to three times more likely to develop the disease than those with negative family history. These women tend to develop breast cancer at much younger age and have higher incidence of bilateral disease. (Chap et al., 2001) This agreement in findings was explained that may be due to equality in the sample size.

Age is an important non-modifiable risk factor for many diseases, especially malignant diseases. The present study findings point to a statistically significant difference between breast cancer patients and control regarding their age, where more than half of women with breast cancer were in the age group 40 years or older.

In agreement with this finding, Singh et al., (2004) study about the natural history of breast cancer in the elderly which was carried out in Germany, reported that the incidence of breast cancer increased with age. While only one in 225 women aged <40 years develops breast cancer, the rate increases to one in 24 for women aged 40-59 years and to one in 14 for women aged 60-79 years. This agreement in findings was explained that there was equality in the age in both studies for women with breast cancer.

In the same respect, Benz, (2008) study which conducted in Singapore about impact of aging on the biology of breast cancer, demonstrated that breast cancer shows a bimodal distribution with respect to age, and specific pathological subtypes are related to different ages at diagnosis.
Also the present study found that there was no significant difference regarding null parity between menopausal and non-menopausal women. In agreement with this study Russo et al., (2005) study about the protective role of pregnancy in breast cancer which was carried out in Japan, found that both pre- and post-menopausal nulliparous women were at increased risk for developing breast cancer. Also Phipps et al., (2011) showed that reproductive factors are associated with breast cancer risk regardless of age or menopausal status.

Also the present study found that there was no significant difference regarding using oral contraceptive with menopausal status. In consistent with this study Newcomer et al., (2003) study which was conducted in United State about oral contraceptive use and risk of breast cancer by histologic type, found that use of oral contraceptives was elevated for women of all ages.

Regarding dietary factors, the present study found that there was a significant difference among menopausal and non-menopausal cases in study group. In agreement with this study, Munsell et al., (2014) study about body mass index and breast cancer risk according to postmenopausal estrogenprogestin use and hormone receptor status which was carried out in Japan, concluded that dietary factors were inversely associated with breast cancer among younger women and positively dietary factors were positively associated with risk for older women.this agreement in these findings was explained that number of menopausal and non menopausal women in study and control groups was not equal in these studies.

\section{Conclusion}

In conclusion, the findings of the present study support that there is a statistically significant relation between reproductive, menstrual, familial factors, and breast cancer. Women who had family history of breast cancer, younger age at menarche, menstrual irregularities, late age at menopause are at a higher risk of breast cancer.

\section{Recommendations}

- In the light of the main study findings, the following recommendations are proposed. Health education programs regarding breast cancer, risk factors, early detection and screening programs should be provided through nurses working in care settings, Nurses should provide practical training about breast self-examination, especially for those women who are at higher risk of breast cancer In order to confirm the relation between reproductive, 
menstrual and familial factors and breast cancer, pre and post menopause, follow-up prospective studies are suggested to determine the actual risk.

\section{References}

1. Aboserea, M., Abdelgawad, M., \& wafik, W., (2011): Early Detection of Breast Cancer among Females at Fakous District, Sharqia Governorate, Egypt, and Life Science Journal. 8, (1), 196- 203. http://www.jofamericanscience.org

2. Afonso, N., (2009): Women at High Risk for Breast Cancer-What the Primary Care Provider Needs to Know. The Journal of the American Board of Family Medicine; 22 (1): 43-50

3. Ahmadian, M., \& Asnarulkhadi, A., (2012): A model for community participation in breast cancer prevention in Iran. Asian Pac J Cancer Prev, 13, 2419-23

4. Albrektsen, G., Heuch, I., Thoresen, S., \& et al., (2006): Family history of breast cancer and short-term effects of childbirths on breast cancer risk. Int J Cancer; b 119(6):1468-74.

5. Antoniou, A., Shenton, A., Maher, E., \& et al. (2006): Parity and breast cancer risk among BRCA1 and BRCA2 mutation carriers. Breast Cancer Res.; 8(6):R72.

6. Asnarulkhadi, S. and Ahmadian, M., (2012): correlates of participation in mammography: a survey among Socio-demographic women aged between 35-69 in Tehran, Iran. Asian Pac J Cancer Prev, 13, 2717-20.

7. Benz, C., (2008): Impact of aging on the biology of breast cancer. Critical Review of Oncology and Hematology; 66: 65-74.

8. Bernstein, L., (2002): Epidemiology of endocrine-related risk factors for breast cancer. J Mammary Gland Biol Neoplasia ،7, 3-15.

9. Britt, K., Ashworth, A., \& Smalley, M., (2007): Pregnancy and the risk of breast cancer. Endocrine-Related Cancer; 14: 907-933.

10. Butler, M., Potischman, A., Newman, B., \& et al., (2000): Menstrual risk factors and earlyonset breast cancer. Cancer Causes Control; 11: 451-458.

11. Chap, I., Barsky, H., Bassett, L., \& et al., (2001): Natural history and pretreatment assessment of breast cancer fifth ed.pp507-532.

12. Committee on Gynecologic Practice. (2009): ACOG Committee Opinion No. 434: induced abortion and breast cancer risk. Obstet Gynecol.; 113(6):1417-8.

13. Dai, Q., Liu, B., \& Du, Y., (2009): Metaanalysis of the risk factors of breast cancer concerning reproductive factors and oral contraceptive use. Frontiers of Medicine in China, 3(4): 452-458

14. Flesch, D., Slanger, T., Mutschelknauss, E., (2008): Risk of different histological types of postmenopausal breast cancer by type and regimen of menopausal hormone therapy. Int $\mathbf{J}$ Cancer; 123(4):933- 41.

15. Gao, T., Shu, O., Dai, Q., \& et al. (2000): Association of menstrual and reproductive factors with breast cancer risk: results from the Shanghai Breast Cancer Study. Int J Cancer.; 87(2):295-300.

16. Howlader, N., Noone, A., \& Krapcho, M., (2012): SEER Cancer Statistics Review, 19752009. Bethesda, MD: National Cancer Institute.

17. Iskandarsyah, A., Klerk, C., Suardi, D., \& et al., (2014): Health locus of control in indonesian women with breast. Cancer: a comparison with healthy women. Asian Pac J Cancer Prev, 15, 9191-7.

18. James, R., (2012): Medical Surgical Nursing, OB-GYN, 3rd ed, pages, 179-180.

19. Kauppila, A., Kyyrönen, P., Hinkula, M., \& et al., (2009): Birth intervals and breast cancer risk. Br J Cancer; 101(7):1213-7, available at www.urac.org.

20. Kotsopoulos, J., Lubinski, J., \& Lynch, T., (2005): Age at menarche and the risk of breast cancer in BRCA1 and BRCA2 mutation carriers. Cancer Causes Control; 16:667 - 74.

21. Lee, J., Robert, J., \& Chen, M., (2009): Breast self-examination, Leukemia/Bone Marrow Transplant Program, Massachusetts General Hospital American Accreditation Health Care Commission Division of Surgery, UCSF, San Francisco, available at www.urac.org.

22. Lin, J., Mason, E., Lee, M., \& et al., (2007): Intakes of calcium and vitamin $\mathrm{D}$ and breast cancer risk in women. Arch Intern Med.; 267(10):1050-1059.

23. Michels, K., Xue, F., Colditz, G., \& et al., (2007): Induced and spontaneous abortion and incidence of breast cancer among young women. Arch Intern Med; 167:814e20.

24. Mohammad, R., Shokouh, T., Abdorrahim, A., \& et al., (2007) : Study on the Relationship Between Breast Cancer and Female Endocrine Conditions, Hormone Therapy and Oral Contraceptive Usage among Women in Yazd, Iran During 2006-2007 Middle-East Journal of Scientific Research 8 (1): 34-39, 2011

25. Munsell, M., Sprague, B., Berry, G., \& et al., (2014): Body mass index and breast cancer risk according to postmenopausal estrogen-progestin use and hormone receptor status. Epidemiol Rev. 36(1):114-36. 
26. Newcomer, L., Newcomb, P., Trentham, A., \& et al., (2003): Oral contraceptive use and risk of breast cancer by histologic type. Int $\mathrm{J}$ Cancer 106:961-964.

27. Ozmen, V., Ozcinar, B., Karanlik, H. \& et al., (2009): Breast cancer risk factors in Turkish women - a University Hospital based nested case control study. World J Surg Oncol.; 7: 37.

28. Phipps, A., Buist, D., Malone, K. \& et al., (2011): Reproductive history and risk of three breast cancer subtypes defined by three biomarkers. Cancer Causes Control 22:399-405. doi:10.1007/s10552-010-9709-0

29. Russo, J., Moral, R., Balogh, G. \& et al., (2005): The protective role of pregnancy in breast cancer. Breast Cancer Res; 7 131-42 .available at: http://www.nccn.org/professionals/physician_gls /f_guidelines.asp.

30. Seth, T., Kotwal, A., Thakur, R., \& et al., (2012): A study on community perceptions of common cancers, determinants of community behaviour and programimplementation in New Delhi, India. Asian Pac J Cancer Prev, 13, 2781 9.

31. Singh, R., Hellman, S., \& Heimann, R., (2004): The natural history of breast cancer in the elderly: Implications for screening and treatment. Cancer; 100: 1807-1813.

32. Stefanidou, M., Maravelias, C., \& Spiliopoulou, C., (2009): Human exposure to endocrine disruptors and breast milk. Endocr Metab Immune Disord Drug Targets; 9(3):26976.

33. Sumitra, S., Mary, B., Susan, L., \& et al., (2007): Reproductive factors and breast cancer risk among older women. Breast Cancer Res Treat 102:365-374 DOI 10.1007/s10549-0069343-4

34. Suzanne, G., Folger, A., Marchbanks. A., \& et al., (2007): Risk of breast cancer associated with short-term use contraceptives Cancer Causes Control 18:189-198 DOI 10.1007/s10552-006-0086-7

35. Tam, C., Martin, L., \& Hislop, G., (2010): Risk factors for breast cancer in postmenopausal Caucasian and Chinese-Canadian women. Breast Cancer Res, 12, 2.

36. Trivers, K., Gammon, M., Abrahamson, P., \& et al., (2007): Association between reproductive factors and breast cancer survival in younger women. Breast Cancer Res Treat; 103(1):93102.

37. Walker, K., Bratton, D., \& Frost, C., (2011): Premenopausal endogenous estrogen levels and breast cancer risk: a meta-analysis. Br J Cancer; 105(9):1451-57.

38. Wiechmann, L., Kuerer, H., (2008 May): "The molecular journey from ductal carcinoma in situ to invasive breast cancer." Cancer. 15; 112(10):2130-42.

39. Wingo, A., Austin, H., Marchbanks, A. \& et al., (2007): Oral contraceptives and the risk of death from breast cancer. Obstetrics and Gynecology; 110: 793-800. 